\title{
CONCURSO PÚBLICO PARA DIRETOR NA ESCOLA ESTADUAL PAULISTA: EXPECTATIVAS DOS ÓRGÃOS CENTRAIS DO ENSINO E CONCEPÇÕES DE DIRETORES
}

\author{
Viviani Fernanda Hojas \\ Universidade Estadual Paulista “Júlio de Mesquita Filho" (UNESP)
}

RESUM0: A partir da análise dos editais e das provas dos concursos públicos para provimento do cargo de diretor de escola realizados na rede estadual de ensino de São Paulo e das concepções de diretores, este artigo pretende identificar as expectativas dos órgãos centrais de ensino em relação à atuação desses profissionais e o pensamento administrativo que supostamente orientou e/ou orienta a administração das escolas públicas paulistas. O estudo dos editais e das provas permitiu observar que o perfil almejado para diretor de escola sofreu alterações significativas ao longo do tempo sob influência de aspectos políticos, econômicos, sociais e educacionais. A investigação das concepções dos diretores, por sua vez, parece reacender a necessidade de construção de uma teoria específica para a atividade administrativa escolar.

Palavras-chave: Administração Escolar. Diretor de escola. Concurso público.

http://dx.doi.org/10.1590/0102-4698132942

* Doutoranda do Programa de Pós-Graduação em Educação da Universidade Estadual Paulista “Júlio de Mesquita Filho" (UNESP). Membro do Centro de Estudos e Pesquisas em Administração da Educação (CEPAE). E-mail: vihojas@hotmail.com 


\title{
PUBLIC CONTEST FOR SCHOOL PRINCIPAL ATPAULISTA STATE SCHOOL: EXPECTATIONS OF THE TEACHING CENTRAL ORGANS AND CONCEPTIONS OF DIRECTORS
}

\begin{abstract}
From the analysis of notices and tests of public contests to fill the position of school principal performed in state schools of São Paulo State and from the conceptions of directors, this article seeks to identify the expectations of central bodies of education regarding the role of these professionals and the administrative thought that supposedly guided and/or directs the administration of public paulista schools. The study of the notices and tests allowed observing that the desired profile for the school principal has changed significantly over time under the influence of political, economic, social and educational aspects. The investigation of the conceptions of directors, in turn, seems to rekindle the need to build a specific theory for the school administrative activity.
\end{abstract}

Keywords: School Administration. School principal. Public contest.

\section{INTRODUÇÃO}

Neste artigo, apresentam-se resultados de pesquisa, subsidiada pela Fundação de Amparo à Pesquisa do Estado de São Paulo (FAPESP), que teve como objetivo analisar os editais e as provas dos concursos públicos para provimento do cargo de diretor de escola realizados na rede estadual de ensino de São Paulo entre 1979 e 2007, bem como as concepções que os diretores concursados têm acerca da função que exerceram e/ou exercem nas escolas. O período delimitado corresponde, respectivamente, ao primeiro processo de seleção de diretores escolares ocorrido após a reformulação da estrutura do sistema oficial de ensino paulista, realizada em meados da década de 1970, e ao último concurso promovido no estado.

A origem da figura do diretor responsável pelo ordenamento do trabalho escolar nos estabelecimentos de ensino primário de São Paulo está associada ao processo de criação e expansão dos grupos escolares, levado a efeito pelos primeiros governos republicanos a partir de $1893^{1}$. De acordo com Meneses (1972), inicialmente, com base no Decreto n ${ }^{\circ} 1.253 / 1904$ que aprovou o Regimento Interno dos Grupos Escolares, o cargo de diretor era provido em comissão, por livre escolha do Diretor Geral de Instrução Pública. A exigência legal era o diploma da Escola Normal, preferencialmente, ou o diploma da Escola Complementar e dois anos de efetivo exercício em grupo escolar ou outro estabelecimento equivalente. Com a aprovação do Decreto-Lei n ${ }^{\circ}$ 12.427/1941 que consubstanciou novas disposições relativas à carreira do magistério público primário, 
a realização de concurso de provas e títulos tornou-se obrigatória entre os professores que contassem quatrocentos dias, pelo menos, de efetivo magistério. A partir de 1946, segundo Meneses (1972), os cargos de diretor passaram a ser providos em caráter efetivo e, mais tarde, ampliaram-se as exigências de formação, podendo efetuar a inscrição no concurso somente os professores primários diplomados pelo Curso de Administradores Escolares ${ }^{2}$ e que tivessem três anos de efetivo exercício no magistério público.

Os grupos escolares foram extintos em meados da década de 1970, com a promulgação da Lei n ${ }^{\circ}$ 5.692/1971, que fixou as diretrizes e bases para o ensino de $1^{\circ}$ e $2^{\circ}$ graus e alterou de maneira significativa o funcionamento das escolas e a organização dos ensinos Elementar e Médio brasileiros. Dentre as modificações introduzidas pelo dispositivo legal, destaca-se a extensão da escolaridade obrigatória - de quatro para oito anos - atingindo a faixa etária dos sete aos catorze anos de idade.

Para cumprir o estabelecido nacionalmente, conforme Rus Perez (2000), a equipe do governo Laudo Natel (1971-1975) elaborou o Plano Estadual de Implantação da Reforma do Ensino de $1^{\circ}$ e $2^{\circ}$ Graus. Apesar dos estudos realizados naquele momento, as mudanças no sistema educacional paulista foram efetivadas somente no governo seguinte, com a publicação do Decreto $\mathrm{n}^{\circ} 7.400 / 1975$, que estabeleceu a estrutura da rede oficial de ensino do estado ${ }^{3}$. De acordo com o documento, a nova estrutura da rede pública de ensino de São Paulo passou a ser composta por Escolas Estaduais de $1^{\circ}$ Grau, Escolas Estaduais de $2^{\circ}$ Grau, Escolas Estaduais de $1^{\circ}$ e $2^{\circ}$ Graus e Centros Estaduais Interescolares.

Com as mudanças introduzidas no sistema oficial de ensino paulista e o aumento da população atendida nas escolas, a administração escolar foi tornando-se um processo cada vez mais complexo, produzindo efeitos significativos no trabalho dos diretores escolares. Nesse sentido, a análise dos concursos públicos para provimento do cargo de diretor de escola realizados a partir do final dos anos 1970 pode constituir um importante elemento para investigar as novas atribuições conferidas a esse profissional.

Vale destacar que, no período considerado, o estado de São Paulo esteve sob o comando de diferentes gestões governamentais, marcadas por variações em seus planos, propostas, metas e realizações na área educacional. Os governos Paulo Egydio Martins (1975-1979) e Paulo Maluf (1979-1983), ambos da Arena (Aliança Renovadora Nacional), integraram o grupo de mandatos indicados pelo regime 
militar. A partir de 1983, os governadores passaram a ser eleitos diretamente pela população, sendo os três primeiros pertencentes ao PMDB (Partido do Movimento Democrático Brasileiro), a saber: André Franco Montoro (1983-1986); Orestes Quércia (1987-1990) e Luiz Antonio Fleury Filho (1991-1994). Os mandatos subsequentes foram confiados ao PSDB (Partido da Social Democracia Brasileira), na seguinte ordem: Mário Covas (1995-1998); Mário Covas/Geraldo Alckmin (1999-2002); Geraldo Alckmin/Cláudio Lembo (2003-2006) e finalmente José Serra (2007-2010).

Importa registrar também que a reflexão acerca das distintas maneiras de conduzir o acesso ao cargo de diretor de escola utilizadas no Brasil e de suas relações com a democratização da educação, apesar de relevante e necessária, excede os objetivos deste texto. Sendo assim, a partir do estudo dos editais e das provas dos seis processos de seleção de diretores realizados na rede pública de ensino paulista entre 1979 e $2007^{4}$ e das concepções dos diretores que realizaram tais concursos, foram aprovados e assumiram o cargo, buscou-se identificar as expectativas dos órgãos centrais do ensino do estado de São Paulo em relação à atuação desses profissionais, bem como o pensamento administrativo que supostamente orientou e/ou orienta a administração das escolas públicas paulistas.

As provas dos referidos concursos foram encontradas no arquivo do Departamento de Recursos Humanos (DRHU) da Secretaria da Educação do Estado de São Paulo, exceto aquelas aplicadas no concurso de $1979^{5}$. No DRHU, também, foram obtidas informações sobre as datas de publicação dos editais dos concursos que, posteriormente, foram reunidos mediante consulta ao site da Imprensa Oficial de São Paulo ${ }^{6}$. A localização dos profissionais que atuaram e/ou atuam na direção escolar foi feita com o apoio da Diretoria de Ensino de uma cidade do interior paulista. De acordo com informações fornecidas por uma funcionária do local, foi elaborada uma lista com os nomes de alguns diretores e dos respectivos concursos que eles realizaram. A partir dessa lista prévia, foi realizado o contato pessoal e, posteriormente, foram feitas entrevistas com um diretor de cada um dos concursos, em um total de seis entrevistados que, ao longo do texto, serão denominados de D1, D2, D3, D4, D5 e D6, seguindo a ordem dos concursos que eles prestaram.

As entrevistas foram de tipo semiestruturado, cuja característica principal, segundo Manzini (2003), consiste na elaboração prévia de um roteiro com a função de auxiliar o pesquisador a conduzir a entrevista para o objetivo pretendido. Dentre as questões norteadoras, 
destacam-se: Qual a função do diretor na escola? O que um diretor de escola precisa saber para atuar na direção escolar? Para ser diretor de escola é preciso ser professor? Administrar uma escola é equivalente a administrar uma empresa?

Para o desenvolvimento do estudo, tomou-se como subsídio teórico a trajetória do conhecimento em Administração da Educação produzido no país. As primeiras publicações nesse campo, baseadas na Teoria Geral da Administração, defendiam a adoção de princípios administrativos empresariais nos estudos e práticas de administração escolar (CARNEIRO LEÃO, 1939; RIBEIRO, 1952; LOURENÇO FILHO, 1963; ALONSO, 1976). Entretanto, no final da década de 1970 e nos anos 1980, os autores propuseram a construção de uma fundamentação teórica específica para a atividade administrativa realizada nas escolas (ARROYO, 1979; FÉLIX, 1984; ZUNG, 1984; PARO, 1986; SILVA JR, 1986).

A análise efetuada evidenciou que o movimento teórico no campo da Administração da Educação produziu reflexos nos concursos promovidos na rede estadual de ensino paulista que, por apresentarem características comuns, foram estudados de forma agrupada. A primeira seção trata dos concursos realizados em 1979 e 1982, marcados pela valorizaçãode conhecimentos de natureza eminentemente técnica e de aspectos normativos que envolvem a função do diretor de escola. Na seção seguinte, são abordados os concursos de 1988 e 1998, caracterizados pela defesa de uma orientação teórica específica para a Administração Escolar e da participação dos diferentes segmentos escolares nos processos decisórios da escola. A última seção tem como foco de análise os concursos realizados em 2001 e 2007, marcados pela escassez de estudos específicos voltados para a teoria administrativa escolar e pela ênfase na gestão da escola, considerada a principal responsável pelos resultados finais do processo educativo.

\section{OS CONCURSOS DE 1979 E 1982: RACIONALIDADE TÉCNICA E NORMATIZAC̣ÃO}

Conforme assinalado inicialmente, as modificações introduzidas no sistema de ensino paulista na gestão Paulo Egydio Martins (1975-1979), com vista a atender às disposições contidas na Lei $n^{\circ}$ 5.692/1971, geraram uma série de dificuldades no interior das escolas e tiveram de ser enfrentadas pela equipe escolar e pelos profissionais que assumiram a direção desses estabelecimentos de ensino. De acordo com a diretora que vivenciou tal processo ao ser aprovada no concurso promovido em 1979: 
[...] quando eu fiz o concurso para diretor de escola, já não foi para grupo escolar, para o ensino primário, mas foi o primeiro concurso para $1^{\circ}$ e $2^{\circ}$ Graus. E as escolas viviam um momento extremamente complicado e difícil, porque num momento em que foram juntados os professores dos níveis diferentes, o professor primário, como professor polivalente, dando conta de todas as disciplinas e tal e, na mesma escola, a partir da $5^{\text {a }}$ série, os professores especialistas por disciplinas, havia sim... animosidade. (D1, 2010).

De acordo com Rus Perez (2000, p.87), a expansão massiva do atendimento nas escolas trouxe grandes desafios ao governo subsequente, liderado por Paulo Maluf (1979-1983). Partindo do pressuposto de que já havia cobertura integral da demanda, com ampla oferta de vagas, tal governo elegeu como meta a manutenção do equilíbrio do atendimento dentro de um padrão compatível com a necessária preocupação com a melhoria da qualidade de ensino.

A profissional que assumiu o cargo diretivo após aprovação no concurso realizado no início dos anos 1980 considera que a democratização do ensino, com a ampliação das oportunidades de acesso à escola e o aumento no número de anos de escolaridade obrigatória, assumiu uma dimensão meramente quantitativa. Em suas palavras:

[...] a partir do instante em que todo mundo veio para a escola, nós não garantimos qualidade. O que nós fizemos não foi democratizar a educação, foi massificar a educação, não é? Porque a gente garantiu que todo mundo tivesse aqui, mas não demos para ninguém a melhor escola. Uma escola democrática seria aquela que conseguisse garantir a todos um bom ensino. Nós não fizemos isso. Nós conseguimos, na verdade, um movimento de massificação da escola. (D2, 2010).

Os dois concursos em tela exigiram como requisitos para a inscrição que o candidato fosse portador do diploma de licenciatura plena em Pedagogia com habilitação em Administração Escolar e tivesse, no mínimo, três anos de exercício no magistério na rede oficial de ensino do estado de São Paulo.

Tais exigências sugerem que a intenção dos órgãos centrais do ensino paulista era trazer para a direção das escolas profissionais devidamente qualificados que apresentassem conhecimentos relativos à atividade administrativa escolar, provenientes do estudo de disciplinas específicas e, ao mesmo tempo, saberes de natureza didático-pedagógica advindos da formação e da experiência docente.

$\mathrm{Na}$ concepção da diretora do concurso de 1979, a formação e a experiência docente oferecem ao diretor de escola condições de interpretar e encaminhar mais satisfatoriamente as questões educacionais. Em suas palavras: “[...] o diretor de escola, antes de tudo, ele tem que ser um educador. Se ele for um educador, ele 
terá boas chances de aprender as especificidades do seu cargo. E, continuando educador, desempenhar bem a sua função" (D1, 2010). A profissional que prestou o concurso de 1982 também compartilha desse pensamento e enfatiza que, para a organização do trabalho em uma escola, é importante que o diretor tenha uma formação bem fundamentada na área educacional:

\footnotetext{
Você tem que conhecer da administração, não é? [...] e, principalmente, eu acho que ele tem que ter a formação de educador. Que é uma formação de natureza filosófica, sociológica, antropológica e psicológica. Então, quer dizer, essa formação do educador, essa visão de educação, essa visão mais plena de educação que eu acho que às vezes falta. E aí quando falta a visão do educador a burocracia se impera. Porque o diretor se perde na burocracia porque ele não tem a visão de escola como um todo. (D2, 2010).
}

No que se refere à bibliografia de referência, os editais dos dois concursos apresentaram uma lista expressiva de livros, artigos, decretos, pareceres e deliberações. As publicações sugeridas aos candidatos, com questões teórico-conceituais voltadas para a atividade administrativa escolar, reuniram autores nacionais e internacionais (COOMBS, 1976; ALONSO, 1976; GRIFFITHS, 1977; KIMBROUGH, 1977; RIBEIRO, 1978; BEEBY, 1973; HERSEY; BLANCHARD, 1976; SERGIOVANNI; CARVER, 1976).

Nesses livros e artigos, é comum a defesa da transposição de princípios administrativos aplicados nas empresas para os estudos e as práticas de administração escolar sob o argumento de que tais princípios seriam automaticamente aplicáveis à administração de qualquer instituição. Em linhas gerais, tais publicações refletem traços do pensamento predominante no campo da Administração Escolar na época que, fundamentado na Teoria Geral da Administração, buscava identificar a atividade administrativa realizada nas escolas e sistemas de ensino com a administração empresarial.

Quando questionadas se administrar uma escola seria equivalente a administrar uma empresa, no entanto, as profissionais que assumiram a direção escolar no final da década de 1970 e início dos anos 1980 afirmaram que existem diferenças importantes entre as duas administrações:

[...] os critérios são totalmente outros. Ou pelo menos deveriam ser totalmente outros. Quer dizer a finalidade da escola é educar. Então na verdade é isso que tem que nortear a minha aplicação de recursos, que tem que nortear o meu planejamento, que tem que nortear as minhas relações. (D1, 2010).

A empresa visa o lucro. E a escola, em minha opinião, a função social da escola é a humanização. É você constituir sujeitos plenos que tenham condição de uma vida 
digna, que tenham uma vida plena. Então, eu acho que aí não dá para confundir as coisas. [...] A empresa pode descartar aquilo que não funciona e a escola não tem porque fazer isso, pois o sentido dela é outro. (D2, 2010).

As provas aplicadas no concurso promovido em 1979, conforme mencionado anteriormente, não foram localizadas. Com efeito, mediante a análise das provas do processo de seleção realizado em 1982, foi possível identificar que boa parte das questões de Conhecimentos Específicos esteve voltada para a figura do diretor de escola e destacou a sua posição de autoridade e liderança sobre todas as atividades desenvolvidas no ambiente escolar. As perguntas de Conhecimentos Gerais versaram, principalmente, sobre aspectos históricos da educação e da política educacional brasileira, diretrizes e normas da educação nacional e elementos estruturais e formais da rede estadual de ensino paulista. Em termos gerais, as provas do concurso de 1982 permitem inferir que os órgãos centrais do ensino esperavam que o profissional responsável pela direção escolar, no exercício de suas funções, assegurasse a execução das determinações estabelecidas pelas instâncias mais altas do sistema de ensino.

\section{OS CONCURSOS DE 1988 E 1998: ESPECIFICIDADE DA ADMINISTRAÇÃO ESCOLAR E PARTICIPAC̣̃̃O}

Os contextos que antecedem a realização dos concursos de 1988 e 1998 apresentam características bastante distintas, porém, os dois processos de seleção de diretores escolares são caracterizados pela defesa de uma orientação teórica específica para a administração escolar e da participação dos diferentes segmentos escolares nos processos decisórios da escola.

O concurso do final dos anos 1980 foi realizado num momento em que o Brasil, após mais de duas décadas de domínio militar, lutava pela superação do autoritarismo e pela construção de um regime político democrático com a ampliação e a garantia de direitos sociais e civis. Em São Paulo, após ampla negociação com entidades representativas do magistério, houve a reestruturação da carreira com a sanção, pelo governador Franco Montoro (19831986), da Lei Complementar $n^{\circ} 444 / 1985$, que dispõe sobre o Estatuto do Magistério Paulista ${ }^{7}$. A gestão Orestes Quércia (19871990), na sequência, teve como metas educacionais prioritárias a democratização, consubstanciada no fortalecimento dos Conselhos de Escolas, das APMs (Associações de Pais e Mestres) e dos Grêmios Estudantis, e a descentralização, mediante a parceria com os 
municípios e a transformação das Delegacias de Ensino em unidades de despesa (RUS PEREZ, 2000, p.110).

O cenário que antecede a realização do concurso de 1998 foi marcado por reformas setoriais promovidas no Brasile em diversos países da região, que buscaram redimensionar o Estado revestindo-o de novas competências e funções, de modo a adaptá-lo às demandas do processo de globalização, da reestruturação produtiva e da competitividade no mundo empresarial. As principais ações na área educacional do governo paulista no período, sob a liderança de Mário Covas (1995-1998), foram: a criação do Sistema de Avaliação de Rendimento Escolar do Estado de São Paulo (SARESP), a instituição do regime de Progressão Continuada e Nova Reorganização da Rede Física ${ }^{8}$.

Em relação aos requisitos para inscrição, nos dois concursos, o pedagogo com experiência na área educacional continuou sendo considerado o candidato natural para assumir a direção de uma escola e, para tanto, deveria apresentar formação específica em Administração Escolar. A única alteração observada em comparação com os concursos anteriores foi o aumento da exigência de experiência docente, que passou de três para cinco anos.

As bibliografias de referência de ambos os concursos, acompanhando o movimento em curso no campo da Administração da Educação, apresentaram livros e artigos que questionavam a utilização da perspectiva empresarial como fundamento da prática administrativa realizada nas escolas e apontavam a necessidade de encontrar uma base teórica específica para tal atividade (FÉLIX, 1984; PARO, 1986; SILVA JR., 1986). Outros estudos listados nessas bibliografias básicas, no entanto, propunham a aplicação da ciência administrativa voltada principalmente para as empresas na educação (COOMBS, 1976; HERSEY; BLANCHARD, 1976; ANDRADE, 1979; KRAUSZ, 1991).

Ao tentar estabelecer comparações entre administrar uma escola e administrar uma empresa, o profissional que realizou o concurso de 1988 afirma que a complexidade das duas administrações é parecida. Entretanto, ressalta que o administrador escolar precisa de um conhecimento bem fundamentado na esfera educacional, de modo a defender sempre em seu trabalho os valores pertinentes à educação:

Você tem que conhecer de psicologia da aprendizagem, conhecer de didática. Com certeza tem que ter todo um embasamento teórico na área de educação. Eu acho que simplesmente um técnico, vamos supor, com uma formação em administração de empresas, sem formação pedagógica, sem formação na área da educação, não funcionaria, em minha opinião. (D3, 2010). 
Assim como seu colega de profissão, a diretora que prestou o concurso de 1998 reconhece que pode haver elementos semelhantes entre a administração escolar e a administração empresarial, mas considera que não existe identificação entre as duas:

Eu acho que um diretor de escola pode aprender muito com o gerenciamento de uma empresa, mas não é a mesma coisa. [...] Um administrador de empresa iria gerenciar muito bem a parte de dinheiro que vem do estado, a parte de prédio, a parte burocrática de seguir os prazos tudo direitinho e tal. Agora eu gostaria de saber como que ele iria gerenciar um conflito de professor e de aluno que é natural que aconteça, não é? Como é que ele iria levar um projeto pedagógico que tem todo um embasamento ideológico e tem, não adianta [negar]. (D4, 2010).

Diferentemente do concurso promovido em 1982, marcado por perguntas de caráter técnico, as questões dirigidas aos candidatos no processo de seleção realizado em 1988 apresentaram forte teor crítico e chamaram a atenção para as contradições que marcam a organização social capitalista. Seus enunciados, de um modo geral, versaram acerca das relações entre sociedade e educação e enfatizaram a participação da comunidade escolar nos mecanismos decisórios da escola como instrumento de luta pela mudança social. Tais aspectos parecem indicar uma mudança de expectativa em relação à atuação do diretor de escola, que deixa de ser considerado a figura central do ambiente escolar para comprometer-se com o exercício democrático no interior da escola.

As perguntas das provas do concurso realizado na década de 1990 trataram, principalmente, de assuntos como: avaliação, trabalho coletivo, desempenho, qualidade de ensino e prática docente. Em linhas gerais, pode-se inferir que tais perguntas procuraram avaliar a visão de conjunto e estratégica dos profissionais que se candidataram ao cargo de diretor de escola, bem como suas habilidades de organizar e mobilizar a participação da equipe escolar tendo em vista a melhoria da qualidade do ensino.

\section{OS CONCURSOS DE 2001 E 2007: GESTÃO ESCOLAR E GERENCIALISMO EMPRESARIAL}

Em relação aos aspectos contextuais que envolvem a realização dos concursos de 2001 e 2007, pode-se afirmar, em termos gerais, que o Brasil acompanhou a tendência global de fortalecimento de um Estado regulador e avaliador que se encarrega de definir as grandes orientações e os alvos a atingir em diferentes setores e realiza processos avaliativos para identificar se os resultados desejados foram, ou não, alcançados. De acordo com Palma Filho (2010), no âmbito 
estadual, as principais medidas para o setor educacional nas gestões Mário Covas/Geraldo Alckmin (1999-2002) e Geraldo Alckmin/ Cláudio Lembo (2003-2006) foram: o Programa de Municipalização do Ensino Fundamental, o programa de formação continuada denominado "Teia do Saber" e a criação da Escola de Tempo Integral.

Os requisitos para a inscrição nos referidos concursos sofreram alterações significativas em relação aos processos de seleção realizados anteriormente no estado. A formação específica em Administração Escolar deixou de ser uma exigência para os pedagogos, e o tempo exigido de experiência no magistério aumentou de cinco para oito anos. Além disso, profissionais não diplomados em Pedagogia também puderam prestar os concursos, desde que tivessem a experiência no magistério exigida e fossem mestres ou doutores na área de educação?.

A não exigência de formação específica para os pedagogos e a possibilidade de que candidatos com diferentes formações prestem o concurso e assumam o cargo diretivo de uma escola, no entanto, trazem alguns desafios para o estabelecimento de uma identidade profissional e para a atuação do futuro diretor de escola. As capacitações realizadas em serviço, na maioria das vezes, acabam se tornando o único instrumento de apoio e fundamentação para o exercício das funções à frente da direção escolar. Organizados por órgãos centrais do ensino, esses cursos de formação continuada, geralmente, têm seus programas inspirados no gerencialismo empresarial e privilegiam os aspectos tecnocráticos da função do diretor de escola em detrimento das questões sociais e educacionais mais amplas que possibilitam uma melhor compreensão das funções da escola e de suas múltiplas dimensões e relações com a sociedade. Para Oliveira (2008), em tais cursos, o profissional responsável pela direção é, novamente, colocado no centro da estrutura de poder da escola, algo similar ao que fora defendido em outros tempos pelos precursores da Administração Científica do Trabalho na gestão escolar. Além disso, esses treinamentos esvaziam de conteúdo crítico e analítico as atitudes do diretor, atribuindo-lhe o papel de gerente de um negócio que precisa viabilizar-se: a escola.

A entrevistada que realizou o último concurso promovido no estado considera que as capacitações em serviço auxiliam seu trabalho, entretanto, admite que não consegue realizar algumas propostas no cotidiano da escola:

[...] uma das coisas que faz muita diferença na hora de você trabalhar é o embasamento teórico. Tem que ter. Inclusive agora eu estou fazendo um curso 
que o estado está propondo aí de gestão. E eu estava aqui lendo o material e o material é muito bom, é excelente. Mas você olha assim e fala: "Meu Deus, eu tô a anos-luz de conseguir dar conta de fazer isso". (D6, 2010).

A dificuldade em trazer os conteúdos abordados durante a formação continuada para seu ambiente de trabalho pode ser explicada, ao menos em parte, pelo forte apelo à visão gerencial e ao estabelecimento de vínculos estreitos entre a atividade administrativa escolar e a administração empresarial difundidos nessas capacitações.

A tendência de recuperação da gerência empresarial na educação sob o argumento da necessária adequação do sistema escolar e da escola às novas demandas e exigências do mercado também foi observada nas publicações listadas nas bibliografias básicas dos concursos de 2001 e 2007 (MELLO, 1993; MOTTA, 1996; VIEIRA et al., 2003). Outro aspecto que chamou a atenção nas referidas bibliografias foi o predomínio de livros organizados na forma de coletâneas que não apresentam estudos substanciais voltados para a teoria administrativa escolar. Em linhas gerais, os livros e artigos listados discutem questões relacionadas à autonomia, participação, trabalho coletivo e liderança na escola (SCHNECKENBERG, 2000; FERREIRA; AGUIAR, 2001; SANDER, 2005; VIEIRA, 2002; LIBÂNEO et al., 2005).

Sobre a adoção de conceitos e práticas do gerencialismo empresarial nas escolas, a diretora que realizou o concurso de 2001 afirma existir algo específico em seu trabalho e conclui que é praticamente impossível administrar pensando somente nos resultados e nos fins econômicos. Segundo ela:

[...] a administração escolar tem a especificidade de estar lidando com o ser humano. Então daí a diferença, porque uma coisa é você administrar, por exemplo, sei lá... Uma fábrica que o produto ali... A matéria prima você não está lidando com o ser humano. Então eu acho que é uma coisa assim mais impessoal, mais fria, que só busca resultado a qualquer custo e quando a gente está lidando com o ser humano não é bem assim. Porque o ser humano tem as suas especificidades e a gente tem que estar olhando para as diferenças individuais. (D5, 2010).

Diferentemente dos demais entrevistados, a profissional que prestou o concurso de 2007 não atribui tanta importância aos conhecimentos na esfera educacional para atuar na direção de uma escola:

Eu particularmente tenho uma visão que contraria a ideia dos meus colegas diretores. Eu acho que o diretor de escola, ele tem que ter uma formação forte mesmo em Administração voltada para o mercado e nessas técnicas de administração. [...] Tem diretor que você pergunta para ele e ele não tem noção de quanto custa a escola pública, de quanto custa a conta de energia, de quanto 
custa a conta da água, de quanto custa a conta do telefone e que isso tem que ser controlado. Porque o estado não é um nascedouro de dinheiro! (D6, 2010).

Mais adiante, no entanto, reconhece que a atividade administrativa realizada na escola não pode ser exercida por um profissional do âmbito empresarial:

[...] hoje o que se pede é que além dessa visão de sala de aula você tenha essa visão da empresa. Agora pegar o cara da empresa e colocar aqui eu acho que não dá muito certo. Eu acho que não dá muito certo, porque ele não tem essa visão, esse olhar que vem da sala de aula. (D6, 2010).

As provas dos dois concursos apresentaram formato semelhante: uma parte contendo questões objetivas e outra parte composta por questões dissertativas ${ }^{10}$. As questões da parte objetiva pautaram-se, principalmente, em textos legais e publicações elaboradas por centrais de ensino e exigiram dos candidatos conhecimentos acerca da legislação e da política educacional de nível federal e estadual. As perguntas da parte dissertativa apresentaram alguns acontecimentos relacionados ao dia a dia da escola e procuraram avaliar as habilidades de tomar decisões e de resolver problemas dos profissionais que se candidataram ao cargo de diretor de escola.

\section{CONSIDERACְÕES FINAIS}

Mediante a análise dos editais e das provas dos concursos públicos para provimento do cargo de diretor de escola realizados na rede estadual de ensino de São Paulo entre 1979 e 2007 e das percepções dos diretores concursados, este artigo buscou identificar as expectativas dos órgãos centrais do ensino em relação à atuação desses profissionais e o pensamento administrativo que supostamente orientou e/ou orienta a administração das escolas públicas paulistas.

Com base nos requisitos exigidos para a inscrição, nas publicações indicadas aos candidatos relativas à temática da Administração Escolar, e nas questões das provas aplicadas nos referidos concursos, foi possível observar que o perfil almejado para o diretor de escola sofreu alterações significativas ao longo do tempo.

A análise dos concursos realizados em 1979 e 1982 permitiu inferir que o diretor era identificado como aquele profissional que ocuparia posição de especial importância na escola, e cuja função seria a de coordenar o trabalho da equipe escolar para garantir a consecução dos objetivos educacionais e o cumprimento das normas e diretrizes produzidas e determinadas por instâncias superiores do ensino. 
As publicações com conteúdo voltado para a atividade administrativa escolar listadas nas bibliografias de referência, refletindo o movimento teórico no campo da Administração Escolar do período, caracterizaramse pela defesa da adoção de princípios administrativos aplicados em empresas nos estudos e práticas de administração escolar.

Já os concursos promovidos em 1988 e 1998 sinalizaram uma mudança na forma de se conceber o papel do diretor, que deixa de ser considerado a figura central do ambiente escolar para desenvolver seu trabalho de forma mais articulada com todos os envolvidos no processo educativo, de modo a garantir-lhes participação nas decisões que dizem respeito à organização e ao funcionamento da escola. Embora alguns livros e artigos relacionados à administração escolar indicados aos candidatos buscassem fundamento na Teoria Geral da Administração, as publicações sugeridas nas bibliografias básicasque predominaram nas questões das provas foram aquelas que questionavam a utilização da perspectiva empresarial como fundamento da prática administrativa realizada nas escolas e apontavam a necessidade de encontrar uma base teórica específica para tal atividade.

Nos concursos realizados em 2001 e 2007, a figura do diretor volta a ganhar destaque e espera-se que ele possua características necessárias para articular e executar as políticas educacionais no âmbito da escola, pautadas, sobretudo, no desenvolvimento de uma cultura centralizada no desempenho. As publicações na área da Administração Escolar recomendadas nas bibliografias de referência foram marcadas pela ausência de estudos substanciais voltados para a teoria administrativa escolar e pelo resgate da gerência empresarial na educação.

Para os diretores que assumiram o cargo após suas respectivas aprovações nos diferentes concursos, no entanto, apesar de existirem alguns aspectos comuns entre a administração escolar e a administração empresarial, a atividade administrativa desenvolvida nas escolas apresenta certa especificidade. Em linhas gerais, na visão dos entrevistados, o elemento que distingue a escola da empresa é seu objeto de trabalho: o aluno. Sendo assim, a essência do trabalho desenvolvido com ele no ambiente escolar é incompatível com os critérios e mecanismos utilizados nas empresas.

O entendimento que esses profissionais têm da especificidade da escola e de sua administração, de certa maneira, se distancia daquele apresentado por Paro (1986), um dos autores que questiona a transposição de princípios administrativos empresariais para a escola. De acordo como autor, tal especificidade se encontra no processo 
de produção pedagógico, no conceito de produto da educação escolar e na natureza do saber envolvido no processo educativo. Nessa perspectiva, segundo Paro (1986), ao invés de se adotarem os mecanismos administrativos utilizados nas empresas organizadas segundo o modo de produção capitalista, é preciso construir uma teoria própria para a Administração Escolar que considere, sobretudo, os objetivos que se busca alcançar com a escola e a natureza do processo que envolve essa busca.

Com efeito, a tentativa dos profissionais, que estiveram e/ ou ainda estão envolvidos com o dia a dia das escolas, de desvencilhar a administração escolar da administração empresarial, ainda que aparentemente incipiente, traz novos elementos para o debate e reacende a necessidade (ou talvez urgência) da retomada de estudos na área da Administração Escolar que sejam efetivamente capazes de se contrapor, do ponto de vista teórico e prático, à nova onda de importação da gerência empresarial para as escolas e os sistemas de ensino.

\section{REFERÊNCIAS}

ALONSO, M. O papel do diretor na Administração escolar. São Paulo: Difel, 1976.

ANDRADE, N. V. de. Administração em educação. Rio de Janeiro: Livros Técnicos e Científicos, 1979.

ARROYO, M. G. Administração da educação: poder e participação. Educação \& Sociedade, v.1, n.2, p.36-46, jan. 1979.

BEEBY, C. E. O planejamento e o administrador educacional. Tradução de Leonidas Gontijo de Carvalho. Cadernos de Pesquisa, São Paulo, Fundação Carlos Chagas, n.7, p.74-91, jun.1973.

BRASIL. Congresso Nacional. Lei no 5.540, de 28 de novembro de 1968. Fixa normas de organização e funcionamento do ensino superior e sua articulação com a escola média, e dá outras providências. Diário Oficial da União, Brasília, 28 de novembro de 1968.

BRASIL. Congresso Nacional. Lei no 5.692, de 11 de agosto de 1971. Fixa diretrizes e bases para o ensino de $1^{\circ}$ e $2^{\circ}$ graus, e dá outras providências. Diário Oficial da União, Brasília, 11 de agosto de 1971.

CARNEIRO LEÃO, A. Introdução à administração escolar. São Paulo: Nacional. 1939.

COOMBS, P. H. A crise mundial da educação: uma análise de sistemas. São Paulo: Editora Perspectiva, 1976.

DIAS, J. A. O magistério secundário e a função do diretor. 1967. 167 f. Tese (Doutorado em Educação) - Faculdade de Educação, Universidade de São Paulo. São Paulo, 1967.

FÉLIX, M. de F. C. Administração escolar: problema educativo ou empresarial?. São Paulo: Cortez: Autores Associados, 1984.

FERREIRA, N. S. C.; AGUIAR, M. A. da S. (Orgs.). Gestão da educação: impasses, perspectivas e compromissos. São Paulo: Cortez, 2001.

GRIFFITHS, D. E. Teoria da administração escolar. Tradução de José Augusto Dias. São Paulo: Editora Nacional, 1977. 
HERSEY, P.; BLANCHARD, K. H. Psicologia para administradores de empresas: a utilização de recursos humanos. Tradução: Dante Moreira Leite. São Paulo: EPU: Rio de Janeiro: Fundação Nacional de Material Escolar, 1976.

KIMBROUGH, R. B. Princípios e métodos de administração escolar. Tradução: Loyde Amália Faustini e Helena Maria Bicalho Behar. São Paulo: Saraiva, 1977.

KRAUSZ, R. R. Compartilhando o poder nas organizações. São Paulo: Nobel, 1991.

LIBÂNEO, J. C et al. (Orgs.). Educação escolar: políticas, estrutura e organização. 2. ed. São Paulo: Cortez, 2005.

LOURENÇO FILHO, M. B. Organização e administraşão escolar. São Paulo: Melhoramentos, 1963.

MANZINI, E. J. Considerações sobre a elaboração de roteiro para entrevista semiestruturada. In: MARQUEZINE, M. C. et al. (Orgs.). Colóquios sobre pesquisa em educação especial. Londrina: Eduel, 2003.

MELLO, G. N. de. Cidadania e competitividade: desafios educacionais do terceiro milênio. São Paulo: Cortez, 1993.

MENESES, J. G. de C. Direção de grupos escolares: análise de atividades de diretores. São Paulo: Centro Regional de Pesquisas Educacionais, 1972.

MOTTA, P. R. Gestão contemporânea: a ciência e a arte de ser dirigente. Rio de Janeiro: Record, 1996.

NEUBAUER, R. Descentralização da educação no estado de São Paulo. In: COSTA, V. L. C. (Org.). Descentralização da educação: novas formas de coordenação e financiamento. São Paulo: FUNDAP; Cortez, 1999.

OLIVEIRA, D. A. Mudanças na organização e na gestão do trabalho na escola. In: OLIVEIRA, D. A.; ROSAR, M. de F. F. (Orgs.). Política e gestão da educação. 2.ed. Belo Horizonte: Autêntica, 2008.

PALMA FILHO, J. C. A política educacional do estado de São Paulo (1983-2008). Educação \& Linguagem, São Paulo, v.13, n. 21, p. 153-174, jan./jun. 2010.

PARO, V. H. Administração escolar: introdução crítica. São Paulo: Cortez: Autores Associados, 1986.

RIBEIRO, J. Q. Ensaio de uma teoria da administração escolar. São Paulo: FFCL/USP, Boletim 158, 1952.

RIBEIRO, J. Q. Ensaio de uma teoria da administração escolar. Edição revista, anotada e ampliada por João Gualberto de Carvalho Meneses. São Paulo: Saraiva, 1978.

RUS PEREZ, J. R. Avaliação, impasses e desafios da educação básica. Campinas: Editora da Unicamp; São Paulo: Annablume Editora, 2000.

SANDER, B. Políticas públicas e gestão democrática de educação. Brasília: Líber Livro, 2005.

SÃO PAULO. Assembleia Legislativa do Estado. Decreto $n^{\circ} 1.253$, de 28 de novembro de 1904. Aprova e manda observar o Regimento Interno dos Grupos Escolares. Diário Oficial do Estado, São Paulo, $1^{\circ}$ de dezembro de 1904, p.1.

SÃO PAULO. Assembleia Legislativa do Estado. Decreto n ${ }^{\circ} 7.400$, de 30 de dezembro de 1975. Estabelece a estrutura da rede oficial de ensino do estado e dá providências correlatas. Diário Oficial do Estado, São Paulo, 31 de dezembro de 1975, p.23.

SÃO PAULO. Assembleia Legislativa do Estado. Decreto no 7.510, de 29 de janeiro de 1976. Reorganiza a Secretaria de Estado de Educação. Diário Oficial do Estado, São Paulo, 30 de janeiro de 1976, p.2.

SÃO PAULO. Assembleia Legislativa do Estado. Decreto-Lei no 12.427 , de 23 de dezembro de 1941. Consubstancia novas disposições relativas à carreira do magistério público primário, e dá outras providências. Diário Oficial do Estado, São Paulo, 24 de dezembro de 1941, p.1. 
SÃO PAULO. Assembleia Legislativa do Estado. Lei Complementar no 444, de 27 de dezembro de 1985. Dispõe sobre o Estatuto do Magistério Paulista e dá providências correlatas. Diário Oficial do Estado, São Paulo, 31 de dezembro de 1985, p.1.

SCHNECKENBERG, M. A relação entre política pública de reforma educacional e a gestão do cotidiano escolar. Em aberto, Brasília, v.7, n. 72, p. 113-124, fev./jun. 2000.

SERGIOVANNI, T. J.; CARVER, F. D. O novo executivo escolar: uma teoria da administração. Tradução: Loyde Amália Faustini e Martha Faustini Egg. São Paulo: EPU, 1976.

SILVA JR, C. A. da. Organização do trabalho na escola: a prática existente e a teoria necessária. Cadernos de Pesquisa, São Paulo, Fundação Carlos Chagas, n.59, p.73-76, nov. 1986.

VIEIRA, A. T. et al. (Orgs.). Gestão educacional e tecnologia. São Paulo: Avercamp, 2003.

VIEIRA, S. L. Refletindo sobre a função social da escola. In: (Org.). Gestão da escola: desafios a enfrentar. Rio de Janeiro: DP\&A, 2002.

ZUNG, A. Z. K. A teoria da administração educacional: ciência e ideologia. Cadernos de Pesquisa, São Paulo, n.48, p.39-46, fev. 1984.

\section{NOTAS}

${ }^{1}$ No que se refere ao Ensino Secundário, conforme Dias (1967), a figura do diretor já aparece com a primeira escola secundária criada no estado de São Paulo, em 1892. Cumpre mencionar também que, durante muito tempo, esse tipo de estabelecimento de ensino, diferentemente da escola primária, atendeu a uma clientela bastante restrita proveniente das camadas média e superior da população.

${ }^{2} \mathrm{O}$ primeiro Curso de Administradores Escolares de São Paulo funcionou no Instituto de Educação "Caetano de Campos", na capital. Posteriormente, esse curso foi sendo instalado nos novos Institutos de Educação criados no estado. A formação de administradores escolares em nível médio foi realizada até o início da década de 1970, pois, nos termos do artigo 30 da Lei ${ }^{\circ} 5.540 / 1968$, o preparo desses profissionais passou a ser realizado no nível superior.

${ }^{3}$ No ano seguinte, foi publicado também o Decreto n ${ }^{\circ} 7.510 / 1976$ que reorganiza a Secretaria de Estado de Educação. Dentre as modificações introduzidas por esse dispositivo legal, destaca-se a criação da Coordenadoria de Ensino da Grande São Paulo (COGSP) e da Coordenadoria de Ensino do Interior (CEI), ambas com suas respectivas Divisões Regionais de Ensino (DREs) e Delegacias de Ensino (DEs).

${ }^{4}$ Os concursos foram realizados nos anos de 1979, 1982, 1988, 1998, 2001 e 2007.

5 Segundo a funcionária do DRHU, as provas relativas a esse concurso não se encontravam no arquivo e provavelmente foram descartadas em decorrência da falta de espaço suficiente para o armazenamento.

${ }^{6} \mathrm{O}$ endereço do site é www.imprensaoficial.com.br.

${ }^{7}$ Tal dispositivo legal instituiu modificações importantes no que diz respeito à organização do trabalho nas escolas públicas paulistas. Dentre elas, destaca-se a tentativa de promover a participação efetiva de todos os membros escolares no processo de tomada de decisão mediante a constituição do Conselho de Escola de caráter deliberativo.

${ }^{8} \mathrm{~A}$ organização das escolas públicas estaduais paulistas até então, apoiada na Lei no 5.692/1971, reunia em um único prédio todas as séries do ensino fundamental e, frequentemente, o ensino médio. A partir de 1996, sob o argumento de que um agrupamento 
dos alunos de acordo com a faixa etária era essencial para o aprimoramento do ensino, foram criadas escolas especializadas no atendimento de crianças menores ( $1^{\mathrm{a}}$ a $4^{\mathrm{a}}$ séries) e de préadolescentes e adolescentes ( $5^{\mathrm{a}}$ a $8^{\mathrm{a}}$ séries e ensino médio). Para mais informações sobre a reorganização do ensino no estado de São Paulo, ver Neubauer (1999).

${ }^{9}$ No concurso realizado em 2007 , puderam efetuar inscrição também profissionais com pósgraduação em nível de especialização em Gestão Escolar de no mínimo 800 horas.

${ }^{10}$ No concurso de 2001 os candidatos foram submetidos ainda a uma Prova Prática de Informática na qual tiveram de executar algumas tarefas básicas no computador.

Recebido: 03/04/2014

Aprovado: 01/10/2014

Contato:

Universidade Estadual Paulista Júlio de Mesquita Filho Faculdade de Filosofia e Ciências - Campus de Marília Av. Hygino Muzzi Filho, 737 Campus Universitário Marília |SP | Brasil

CEP 17.525-900 